\title{
Commentary
}

\section{Predictability of verapamil steady-state plasma levels from single-dose data explained}

\author{
John G. Wagner, Ph.D. Ann Arbor, Mich. \\ College of Pharmacy and Upjohn Center for Clinical Pharmacology, The University of \\ Michigan Medical Center
}

Wagner et al. ${ }^{4}$ used data of Freedman et al.$^{1}$ and Shand et al. ${ }^{2}$ to construct a plot of $\overline{\mathrm{C}}_{\mathrm{ss}} /$ (AUC $0-\tau / \tau$ ), which is reproduced in this article as Fig. 1. The slope of the line in Fig. 1 is 2.41 , much larger than the value of unity expected for a linear system. I was told through the Food and Drug Administration that this figure has been misunderstood by several people as applying universally to all first-pass drugs. This is an unfortunate and erroneous conclusion. A satisfactory explanation of the high correlation indicated by the figure has been derived and is presented below.

\section{Methods}

The Appendix shows the derivation of two new equations that give $V_{m}$ and $K_{m}$ of the Michaelis-Menten equation as functions of $\mathrm{R}$, $\mathrm{Cl}_{\mathrm{i}}$, and $\mathrm{Cl}_{\mathrm{ss}}$. These two equations (Eqs. 9 and

\footnotetext{
Received for publication Jan. 12, 1984; accepted Jan. 27, 1984.

Reprint requests to: John G. Wagner, Ph.D., Upjohn Center for Clinical Pharmacology, The University of Michigan Medical Center, Ann Arbor, MI 48109-1065.
}

11) apply to both the venous equilibration model and the sinusoidal perfusion model, ${ }^{3}$ but the numerical values of $\mathrm{Cl}_{\mathrm{i}}, \mathrm{Cl}_{\mathrm{ss}}, \mathrm{V}_{\mathrm{m}}$, and $\mathrm{K}_{\mathrm{m}}$ obtained with both theories will be different (this will be discussed in another article). In Fig. 1, the ratio of ordinate/abscissa is essentially the same as the slope of the least-squares line forced through the origin and is equal to the following when Eqs. 4, 5, and 7 of the Appendix are used:

$$
\begin{aligned}
& \frac{\overline{\mathrm{C}}_{\mathrm{s \varphi}}}{\text { AUC } 0-\infty / \tau}=\frac{\text { AUC } 0-\tau / \tau}{\text { AUC } 0-\infty / \tau}= \\
& \begin{aligned}
\frac{\text { AUC } 0-\tau}{\text { AUC } 0-\infty}=\frac{\frac{D_{s}}{A U C 0-\infty}}{\frac{D_{m}}{A U C ~ 0-\tau}} & =\text { (Eq. 1) } \\
\frac{C l_{1}}{C I_{s s}} & =\frac{V_{m}}{V_{m}-R}
\end{aligned}
\end{aligned}
$$

If intersubject variation of $V_{m}$ is small (i.e., narrow distribution), Eq. 1 indicates that all the points of a plot of $\overline{\mathrm{C}}_{\mathrm{ss}} /(\mathrm{AUC} 0-\infty / \tau)$ would fall near a straight line, with a slope equal to $V_{m} /$ $V_{m}-R$ ). Table I lists the estimated values of $\mathrm{Cl}_{i}$, 
Abbreviations used

AUC $0-\tau: \quad$ AUC during $\tau$ at steady state AUC $0-\infty$ : AUC from zero to infinity after $\mathrm{D}_{\mathrm{s}}$

$\mathrm{Cl}_{\mathrm{i}}$ : Intrinsic clearance of drug, equal to $V_{m} / K_{m}$ and estimated from $D_{\mathrm{s}} / \mathrm{AUC} 0-\infty$ after a low $\mathrm{D}_{\mathrm{s}}$

$\mathrm{Cl}_{\mathrm{ss}}$ : Clearance of drug at steady-state, corresponding to $\mathbf{R}$

$\mathrm{C}_{\mathrm{ss}}$ : Steady-state plasma concentration after oral administration at a constant $\mathbf{R}$

$\overline{\mathrm{C}}_{\mathrm{ss}}$ : $\quad$ Average steady-state plasma concentration after intermittent oral therapy when $D_{m}$ given every $\tau$ hours

$\mathbf{D}_{\mathrm{m}}$ : Maintenance dose of the drug administered orally

$D_{\mathrm{s}}$ : Single dose of drug

$\mathrm{K}_{\mathrm{m}}$ : Michaelis constant

r: Correlation coefficient for regression of $\mathrm{Y}$ on $\mathrm{X}$

$R$ : Dosing rate, equal to $D_{m} / \tau$

$\tau$ : Dosing interval

$\mathrm{V}_{\mathrm{m}}$ : Maximal velocity of metabolism

$\mathrm{v}$ : Instantaneous rate of metabolism at time $t$, corresponding to $\mathrm{C}_{\mathrm{ss}}$ or $\overline{\mathrm{C}}_{\mathrm{ss}}$

$\mathrm{Cl}_{\mathrm{ss}}, \mathrm{V}_{\mathrm{m}}, \mathrm{K}_{\mathrm{m}}, \mathrm{Cl}_{\mathrm{i}} / \mathrm{Cl}_{\mathrm{ss}}, \mathrm{V}_{\mathrm{m}} /\left(\mathrm{V}_{\mathrm{m}}-\mathrm{R}\right)$, and $\overline{\mathrm{C}}_{\mathrm{ss}} /$ (AUC $0-\infty / 6$ ). Note that the numeric values of the last three ratios are the same for each subject and the averages are equal to 2.48 , essentially the same as the slope of the least-squares line found through the origin in Fig. 1, namely 2.41 . Most noteworthy in Table $I$ is the very low intersubject variation in $V_{m}$, with a mean of 575 $\mathrm{mg} / \mathrm{day}$, a coefficient of variation of $10.7 \%$, and a range of 496 to $711 \mathrm{mg} / \mathrm{day}$. It is this relative constancy of $V_{m}$ that causes the points in Fig. 1 to be grouped along a straight line with a relatively low degree of scatter.

\section{Discussion}

It is feasible with a different first-pass drug than verapamil that $V_{m}$ would vary more between subjects and hence there would be more scatter in the plot of $\overline{\mathrm{C}}_{\mathrm{ss}} /($ AUC $0-\infty / \tau)$. Hence one should not conclude from the nature of the plot for verapamil (Fig. 1) that other first-pass drugs give similar plots.

Wilkinson et al. ${ }^{5}$ defined $\mathrm{Cl}_{\mathrm{i}}$ as the volume of

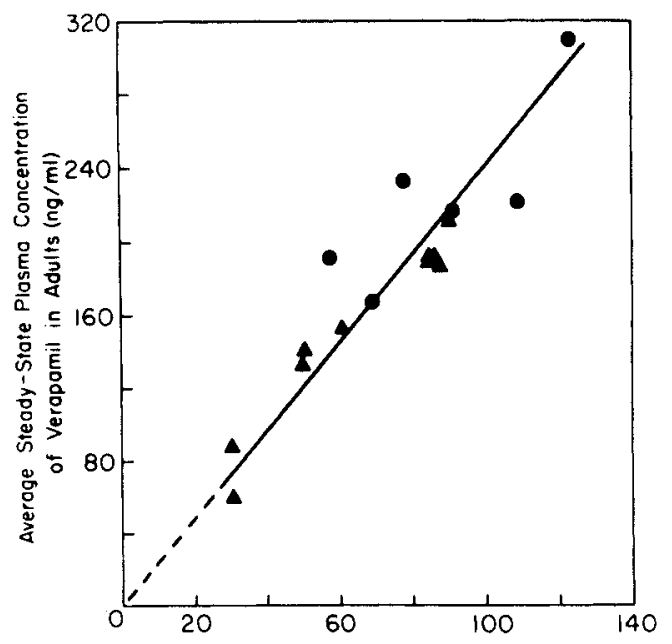

AUC $0^{-\infty} / 6$ After a Single Oral Dose in Adults (ng/ml)

Fig. 1. Plot for predicted $\overline{\mathrm{C}}_{\mathrm{ss}}$ of verapamil from single-dose oral data in adults. Triangles represent data of Freedman et $\mathrm{al}^{1}$ and circles those of Shand et al. ${ }^{2}$ Equation of line is: $\hat{Y}=2.41 X(n=15 ; r=$ 0.923 ; $\mathrm{P}<0.001$ ).

water in the liver cleared of the drug per unit time and equal to any oral dose divided by the oral AUC under first-order conditions, as well as equal to the ratio $V_{m} / K_{m}$ as in Eq. 6 of the Appendix. Many have interpreted this to mean that $\mathrm{Cl}_{\mathrm{i}}$ of a given drug in a given person can vary widely depending on the single oral dose administered. I believe this is a misuse of the intrinsic clearance concept, and that each subject given a certain first-pass drug has only one mean $\mathrm{Cl}_{\mathrm{i}}$, which may exhibit some intrasubject variation in estimation from time to time. However, if there is a trend such that estimated clearance decreases with increase in dose or $\mathbf{R}$, then the highest clearance corresponding to the lowest dose or $\mathbf{R}$ most closely approaches the actual $\mathrm{Cl}_{\mathbf{i}}$. If several different $\mathrm{D}_{\mathrm{s}} \mathrm{s}$ have been given or several different $\mathrm{Rs}$ have been studied at steady state, the best estimate of $\mathrm{Cl}_{\mathrm{i}}$ would be obtained by plotting the estimated clearance against $D_{s}$ or $R$, fitting a straight line to the data with the use of the intercept of the line on the ordinate as the estimate of $\mathrm{Cl}_{\mathrm{i}}$. This follows from Eq. 5 of the Appendix, which indicates that a plot of $\mathrm{Cl}_{\mathrm{ss}} / \mathrm{R}$ will be a straight line with an intercept of $V_{m} / K_{m}$ and a slope equal to 
Table I. Parameter values for verapamil estimated from single-dose and steady-state plasma concentrations

\begin{tabular}{c|c|c|c|c|c|c|c|c}
\hline $\begin{array}{c}\text { Reference for } \\
\text { data source }\end{array}$ & $\begin{array}{c}\text { Subject } \\
\text { No. }\end{array}$ & $\begin{array}{c}C l_{i} \\
(l / m i n)\end{array}$ & $\begin{array}{c}C l_{s s} \\
(l / m i n)\end{array}$ & $\begin{array}{c}V_{m} \\
(\text { mg/day })\end{array}$ & $\begin{array}{c}K_{m} \\
(n g / m l)\end{array}$ & $C l_{i} / C l_{s s}$ & $\begin{array}{c}V_{m} / \\
\left(V_{m}-R\right)\end{array}$ & $\begin{array}{c}C_{s s} / \\
(A U C O / 6)^{*}\end{array}$ \\
\hline \multirow{2}{*}{$\dagger$} & 1 & 2.640 & 1.195 & 585 & 154 & 2.21 & 2.21 & 2.21 \\
& 2 & 4.474 & 1.669 & 510 & 79.2 & 2.68 & 2.68 & 2.68 \\
& 3 & 3.663 & 1.468 & 533 & 101 & 2.49 & 2.50 & 2.49 \\
& 4 & 7.286 & 2.589 & 496 & 47.3 & 2.82 & 2.82 & 2.81 \\
& 5 & 2.597 & 1.179 & 586 & 157 & 2.20 & 2.20 & 2.21 \\
& 6 & 4.415 & 1.612 & 505 & 79.3 & 2.74 & 2.73 & 2.74 \\
& 7 & 2.545 & 1.199 & 605 & 165 & 2.12 & 2.12 & 2.12 \\
& 8 & 2.465 & 1.031 & 547 & 154 & 2.39 & 2.41 & 2.39 \\
& 9 & 7.366 & 3.777 & 657 & 61.9 & 1.95 & 1.95 & 1.95 \\
& 1 & 3.236 & 1.343 & 615 & 132 & 2.41 & 2.41 & 2.40 \\
& 2 & 2.457 & 1.027 & 619 & 175 & 2.39 & 2.39 & 2.39 \\
& 3 & 2.041 & 1.006 & 711 & 242 & 2.03 & 2.03 & 2.03 \\
$\bar{X}$ & 4 & 1.810 & 0.723 & 599 & 230 & 2.51 & 2.51 & 2.50 \\
CV (\%) & 5 & 2.869 & 0.955 & 541 & 131 & 3.00 & 2.99 & 3.01 \\
& 6 & 3.891 & 1.170 & 515 & 91.9 & 3.32 & 3.32 & 3.33 \\
& & 3.583 & 1.463 & 575 & 133 & 2.48 & 2.48 & 2.48 \\
\hline
\end{tabular}

*AUC values of Shand et al. ${ }^{2}$ were adjusted from the actual dosage interval of $8 \mathrm{hr}$ to those expected for a 6-hr dosage interval (as explained in original article).

tR was $320 \mathrm{mg} /$ day, or $80 \mathrm{mg}$ every $6 \mathrm{hr}$.

$\ddagger R$ was $360 \mathrm{mg} /$ day, or $120 \mathrm{mg}$ every $8 \mathrm{hr}$.

$-1 / \mathrm{K}_{\mathrm{m}}$. As indicated by Eq. 6 of the Appendix, $\mathrm{Cl}_{\mathrm{i}}$ is the limit of $\mathrm{Cl}_{s s}$ as $\mathrm{R}$ approaches 0 . First-order kinetics assume that $R$ or $D_{s}$ are small enough that differences in these values will yield essentially the same value of $\mathrm{Cl}_{i}$. In the estimation of the verapamil parameter values in Table I, it has been assumed that the $\mathrm{Cl}_{\mathrm{i}}$ estimated from a single $80-\mathrm{mg}$ dose of Freedman et al. ${ }^{1}$ and the first $120-\mathrm{mg}$ dose of Shand et al. ${ }^{2}$ is the actual $\mathrm{Cl}_{\mathrm{i}}$. If these clearances are less than the true $\mathrm{Cl}_{\mathrm{i}}$, then the reported $\mathrm{K}_{\mathrm{m}}$ and $V_{m}$ are higher than the true values, as can be seen from Eqs. 9 and 11 of the Appendix.

I believe that essentially all drugs that exert a significant first-pass effect will exhibit nonlinear Michaelis-Menten kinetics after oral administration at an $\mathrm{R}$ in the therapeutic range, as a result of the high drug concentrations entering the liver with this route compared with those after intravenous administration. Support for this statement will be published.

\section{Appendix}

When Michaelis-Menten elimination kinetics and the mammillary model with central compartment elimination apply, then $\mathrm{v}$ at steady-state is equal to $\mathbf{R}$ according to Eq. 2:

$$
\mathrm{v}=\mathrm{R}=\frac{\mathrm{V}_{\mathrm{m}} \mathrm{C}_{\mathrm{s}}}{\mathrm{K}_{\mathrm{m}}+\mathrm{C}_{\mathrm{ss}}}
$$

Rearrangement of Eq. 2 gives Eq. 3:

$$
C_{\mathrm{ss}}=\frac{K_{m} R}{V_{m}-R}=\frac{R}{\left(\frac{V_{m}-R}{K_{m}}\right)}
$$

and Eq. 4 follows:

$$
\mathrm{C}_{\mathrm{ss}}=\frac{\mathrm{R}}{\mathrm{Cl}_{\mathrm{ss}}}
$$

By comparing the denominators of Eqs. 3 and 4, we see that:

$$
\mathrm{Cl}_{\mathrm{ss}}=\frac{\mathrm{V}_{\mathrm{m}}-\mathrm{R}}{\mathrm{K}_{\mathrm{m}}}=\frac{\mathrm{D}_{\mathrm{m}}}{\mathrm{AUC} 0-\tau}
$$

Also, for a low $D_{s}$ :

$$
\mathrm{Cl}_{\mathrm{l}}=\frac{\mathrm{V}_{\mathrm{m}}}{\mathrm{K}_{\mathrm{m}}}=\frac{\mathrm{D}_{\mathrm{s}}}{\mathrm{AUC} 0-\infty}=\lim _{\mathrm{R} \rightarrow 0} \mathrm{Cl}_{\mathrm{ss}}
$$

From Eqs. 5 and 6 we obtain Eq. 7: 


$$
\frac{\mathrm{Cl}_{\mathrm{ss}}}{\mathrm{Cl}_{\mathrm{i}}}=\frac{\frac{\mathrm{V}_{\mathrm{m}}-\mathrm{R}}{\mathrm{K}_{\mathrm{m}}}}{\frac{\mathrm{V}_{\mathrm{m}}}{\mathrm{K}_{\mathrm{m}}}}=\frac{\mathrm{V}_{\mathrm{m}}-\mathrm{R}}{\mathrm{V}_{\mathrm{m}}}=1-\frac{\mathrm{R}}{\mathrm{V}_{\mathrm{m}}}
$$

Rearrangement of Eq. 7 yields Eqs. 8 and 9:

$$
\begin{gathered}
\frac{\mathrm{Cl}_{\mathrm{i}}}{\mathrm{Cl}_{\mathrm{ss}}}=\frac{\mathrm{V}_{\mathrm{m}}}{\mathrm{V}_{\mathrm{m}}-\mathrm{R}} \\
\mathrm{V}_{\mathrm{m}}=\frac{\mathrm{R}}{1-\left(\mathrm{Cl}_{\mathrm{ss}} / \mathrm{Cl}_{\mathrm{i}}\right)}
\end{gathered}
$$

From Eqs. 5 and 6 we obtain Eq. 10:

$$
\mathrm{Cl}_{\mathrm{i}}-\mathrm{Cl}_{\mathrm{ss}}=\frac{\mathrm{V}_{\mathrm{m}}}{\mathrm{K}_{\mathrm{m}}}-\frac{\left(\mathrm{V}_{\mathrm{m}}-\mathrm{R}\right)}{\mathrm{K}_{\mathrm{m}}}=\frac{\mathrm{R}}{\mathrm{K}_{\mathrm{m}}}
$$

Rearrangement of Eq. 10 gives Eq. 11:

$$
\mathrm{K}_{\mathrm{m}}=\frac{\mathrm{R}}{\mathrm{Cl}_{\mathrm{j}}-\mathrm{Cl}_{\mathrm{ss}}}
$$

For intermittent oral or intravenous dosing, $\mathrm{R}$ becomes $\mathrm{D}_{\mathrm{m}} / \tau$ and $\mathrm{C}_{\mathrm{ss}}$ becomes $\overline{\mathrm{C}}_{\mathrm{ss}}=\mathrm{AUC} 0-\tau / \tau$. If unchanged drug is excreted in the urine according to first-order kinetics, $R$ in the above equation must be adjusted for urinary excretion of unchanged drug. If there are " $\mathrm{i}$ " metabolites formed in parallel paths, then $\mathrm{V}_{\mathrm{m}} / \mathrm{K}_{\mathrm{m}}$ is replaced by $\Sigma \mathrm{V}_{\mathrm{mi}} / \mathrm{K}_{\mathrm{ml}}$.

\section{References}

1. Freedman SB, Richmond DR, Ashley JJ, Kelly DT: Verapamil kinetics in normal subjects and patients with coronary artery spasm. CLIN PHARMACOL THER 30:644-652, 1981.

2. Shand DG, Hammill SC, Aanonsen L, Pritchett ELC: Reduced verapamil clearance during longterm oral administration. Clin Pharmacol Ther 30:701-703, 1981.

3. Wagner JG: History of pharmacokinetics. Pharmacol Ther 12:537-562, 1981.

4. Wagner JG, Rocchini AP, Vasiliades J: Prediction of steady-state verapamil plasma concentrations in children and adults. Clin Pharmacol THER 32: 172-181, 1982.

5. Wilkinson GR, Wood AJJ, Branch RA, Shand DG: Intrinsic hepatic clearance in cirrhosis. Gastroenterology 75:347-348, 1978. 